\title{
Reciprocal Influences Between Parenting and Adolescent Problem-Solving Behavior
}

\author{
Martha A. Rueter and Rand D. Conger \\ Iowa State University
}

\begin{abstract}
This investigation evaluated the hypothesis that the development of either effective or disruptive adolescent problem-solving behavior is reciprocally associated with the child-rearing strategies of parents. Longitudinal data collected over 3 time points from a large sample of families were analyzed at 1-year and 2-year measurement intervals by using structural equation modeling. Parent and adolescent behavior was assessed by independent observers. Reciprocal parent-adolescent interactions occurred primarily in the presence of disruptive adolescent behavior. Analyses involving positive adolescent behavior produced unidirectional effects from parent behavior to adolescent behavior. Also, reciprocal associations were most evident when the 2-year measurement interval was used.
\end{abstract}

Thirty years ago, Bell (1968) suggested that many correlational findings originally interpreted as showing parent effects on child development could also be seen as child effects on parental behavior. Once considered completely unorthodox, this bidirectional point of view is now widely accepted. Indeed, a host of theories, including Sameroff 's (1975) transactional theory, Bell and Harper's (1977) control system theory, Thornberry's (1987) interactional theory, Conger and Simons's (1997) matching law theory, and Patterson's (1982) theory of coercive family processes, have since extended Bell's original proposals. Each of these theories holds in common the proposition that the behaviors of parents and children influence one another to promote developmental change in both parties over time. Unfortunately, most of the research in this area focuses on interactions between parents and young children. Thus, there exists a need for empirical tests of bidirectional influences between parents and their adolescent children. The purpose of the present study was to evaluate the proposition that the development of either effective or disruptive adolescent problem-solving behavior is reciprocally associated with the child-rearing strategies of parents.

\section{Methodological Issues and Earlier Research}

Although interest in testing models of reciprocal influences between parents and children has grown in recent years (Finkel,

Martha A. Rueter and Rand D. Conger, Center for Family Research in Rural Mental Health and Department of Sociology, Iowa State University.

During the past several years, support for this research has come from multiple sources, including the National Institute of Mental Health (Grants MH00567, MH19734, MH43270, MH48165, and MH51361), the National Institute on Drug Abuse (Grant DA05347), the Bureau of Maternal and Child Health (Grant MCJ-109572), the MacArthur Foundation Research Network on Successful Adolescent Development Among Youth in High-Risk Settings, and the Iowa Agriculture and Home Economics Experiment Station (Project 3320).

Correspondence concerning this article should be addressed to Martha A. Rueter, Center for Family Research in Rural Mental Health, Iowa State University, 2625 North Loop Drive, Suite 500, Ames, Iowa 50010. Electronic mail may be sent to mrueter@iastate.edu.
1995; Lorenz, Conger, Simons, \& Whitbeck, 1995), empirical tests of such models call for a methodological rigor few investigations can attain. For example, when testing a reciprocal hypothesis, a researcher must demonstrate that the stimulus behavior occurred before the elicited behavior. In other words, one must use data measured over time when testing a reciprocal process (Davis, 1985). The choice of the correct length of time between measurement points also presents a challenge (Gollob \& Reichardt, 1987). Depending on the measurement interval used, one might find (a) little or no evidence for reciprocal effects, (b) large reciprocal effects, or (c) different effects at different intervals (e.g., see Sher, Wood, Wood, \& Raskin, 1996). A third issue concerns the measurement of study variables. Because both parent behavior and child behavior are of interest, both must be assessed at each time point (Sameroff, 1975). Also, many investigators recommend the use of multiple, independent informants in the assessment of study variables. Reliance on a single informant can lead to inflation of parameter estimates as a result of method variance effects (Bank, Dishion, Skinner, \& Patterson, 1990; Campbell \& Fiske, 1959; Lorenz, Conger, Simons, Whitbeck, \& Elder, 1991). Finally, the method of analysis must permit simultaneous estimation of both behavioral stability and transactional relationships between parent and child behaviors over time (Lytton, 1990).

Very few studies of reciprocal parent-adolescent influences have met even some of these rigorous requirements. Using a 2-year measurement interval, Vuchinich, Bank, and Patterson (1992) assessed various forms of adolescent antisocial behaviors in several contexts, including at home, in school, and with peers. This investigation found evidence for contemporaneous reciprocity between parental behavior and child antisocial behavior. Strictly speaking, however, these findings do not meet the stringent standards for demonstrating a reciprocal influence because the stimulus variable did not precede the elicited variable in time (Davis, 1985). Thornberry, Lizotte, Krohn, Farnworth, and Jang (1991) used 6-month time lags to demonstrate reciprocal relationships between parenting behavior and child delinquency ("actionable" offenses such as stealing or running away from home). However, the adolescent study participants reported all measures used in this investigation, suggesting that 
method variance probably accounted for some of the robustness in these findings. More recently, studies have found reciprocal associations between parenting behavior and adolescent drinking and drug use using a 1-year measurement interval (Stice \& Barrera, 1995) and associations between parent-child conflict and adolescent problem behaviors (e.g., stealing) using a 6month time lag (Maggs \& Galambos, 1993). Once again, however, all of the variables in these studies relied on self-reports from adolescents.

Across these studies, no consistent measurement interval was used. The measurement intervals ranged from 6 months to 2 years, with the shorter time intervals producing more evidence of parent-child reciprocity. Although these findings seem to suggest that mutual influences in parent-adolescent behaviors are best detected at shorter rather than longer measurement intervals, all of the studies reporting significant reciprocal associations across shorter time periods used the same reporter across measures. Thus, method variance, rather than the shorter measurement interval, may account for the larger number of significant findings at shorter time lags (Bank et al., 1990; Lorenz et al., 1991). In short, the best measurement interval for detecting reciprocal influences between parents and their adolescent children has yet to be determined.

\section{The Conceptual Model}

In developing the theory that guided the present investigation, we relied heavily on the work of Patterson and his colleagues (DeBaryshe, Patterson, \& Capaldi, 1993; Patterson, 1982, 1986; Patterson \& Bank, 1989; Patterson, Bank, \& Stoolmiller, 1990; Vuchinich et al., 1992). This body of research describes a process through which direct interactions between parents and their antisocial children develop into reciprocal patterns of behavior. According to the theory of coercive family processes (Patterson, 1982, 1986), parents with limited child-rearing skills try to control their child with erratic and often hostile family management practices. The child, in turn, responds with his or her own brand of coerciveness in the form of manipulative and antisocial behavior. This cycle of coercive exchanges typically builds until one party gives in and the other "wins." Over time, the frequency and intensity of coercive cycles grow as the child becomes more sophisticated in his or her coercive responses to parental demands, and parents, in an effort to control their increasingly difficult child, intensify their applications of hostility and other ineffective parenting practices. In this way, parentchild interactions develop into a self-perpetuating reciprocal system that elicits and reinforces coercive behavior.

Patterson's theory (Patterson, 1982, 1986) implicates specific parental and specific child behaviors in the establishment of reciprocal parent-child influences. As described earlier, the affective and managerial qualities of parents' child-rearing practices are expected to influence their child's behavior. For the child's part, the theory indicates that the nature of his or her response to parental control attempts and to parent-child confiict influences parenting behavior.

This emphasis on a child's response to differences with his or her parents makes adolescence an important period during which to test these reciprocal interactions. Parent-child conflicts typically occur more frequently during early adolescence than other periods of childhood (Collins, 1990; Conger \& Ge, in press; Hill, 1988; Steinberg, 1981), although the way parents and children respond to conflicts may not originate in adolescence. Indeed, several writers point out that by the time children reach adolescence, they and their parents may have already established characteristic interaction patterns (e.g., Hill, 1993; Paikoff \& Brooks-Gunn, 1991). An investigation of parentadolescent interaction, therefore, probably involves the study of the maintenance or extension of existing interaction patterns.

Conflicts arising during adolescence can serve as a training ground for a child's development of interpersonal problem-solving skills. Parents play an important role in helping to shape the way an adolescent deals with interpersonal problems through their approach to child rearing (cf. Kobak, Cole, Ferenz-Gillies, Fleming, \& Gamble, 1993; Rubenstein \& Feldman, 1993). As the adolescent's sphere of interaction increases, others, such as peers and teachers, also become important to this process. Substantively, an adolescent's response to interpersonal differences is of interest because the ability to resolve conflicts is an important aspect of successful adolescent development (Hauser \& Bowlds, 1990). Indeed, those who experience intense or unresolved conflict with their parents (Forehand, Long, Brody, \& Fauber, 1986; Montemayor, 1983; Robin, Koepke, \& Moye, 1990; Thompson \& Wilsnack, 1987) or with others (Dubow, Tisak, Causey, Hryshko, \& Reid, 1991; Glyshaw, Cohen, \& Towbes, 1989; McCubbin, Needle, \& Wilson, 1985; Sanders, Dadds, Johnston, \& Cash, 1992) are at risk for a number of adjustment problems, including poor school performance, emotional difficulties, alcohol or other drug use, and conduct problems.

In applying Patterson's (1982, 1986) theory to the present investigation, we conceptualized parenting behavior in two forms. First, coercive parental behavior was conceptualized as harsh and erratic child rearing. More specifically, this form of parental behavior includes inconsistent disciplinary practices, lack of involvement in or knowledge of the adolescent's daily activities, lack of follow-through when attempting to gain adherence to rules and standards, and the presence of hostile, angry affect directed toward the child. In contrast to these coercive parental actions, we also conceptualized a noncoercive approach to parenting (nurturant child rearing). This form of parental behavior emphasizes the use of positive means for guiding adolescent behavior. Nurturant child-rearing practices include the use of clear, assertive statements of standards and expectations; positive reinforcement for desired behavior; the use of reasoning and explanations of consequences to gain compliance; and supportive or positive parental affect.

Two forms of adolescent behavior were also conceptualized. Following from Patterson's (1982, 1986) theory, we considered the nature of an adolescent's response to the parental childrearing strategies just described. Specifically, adolescent problem-solving behaviors were assessed during a discussion in which parents and the adolescent tried to resolve disagreements over such things as the delegation of household chores, access to television, or the completion of homework. Coercive adolescent behavior in this problem-solving setting was conceptualized as obdurate, defiant, and defensive and labeled disruptive, inflexible adolescent problem-solving behavior. Noncoercive adolescent behavior (flexible, involved problem-solving behavior) was characterized by cooperative, active involvement in the parent-adolescent problem-solving discussion. 


\section{Study Hypotheses}

In general, we postulated that the interplay between parental behavior and adolescent problem-solving behavior helps to determine and maintain the quality of family interactions. Furthermore, we propose that, through the establishment of this reciprocal system, both parents and children influence the developing character of their own as well as each other's behavior. These general hypotheses were tested under four conditions. The first condition examined the interrelationships among critical, inconsistent parenting behavior and adolescent problem-solving behavior characterized by defensiveness, defiance, or avoidance. Consistent with Patterson's (1982, 1986) theory, we hypothesized a positive relationship between the behavior of adolescents who persistently responded to parental control attempts with obdurate and defiant behavior and subsequent harsh, inconsistent parental behavior. That is, when compared with other parents over the course of the study, parents of disruptive, inflexible adolescents were expected to become relatively more erratic and hostile toward their child. Likewise, the children of critical, unpredictable parents were expected to become relatively more disruptive and inflexible over time in comparison with other adolescents.

The second condition estimated the interrelationships among harsh, inconsistent parenting and adolescent problem-solving behavior characterized by active involvement, cooperation, and patience. On the basis of a host of earlier work attesting to the detrimental effect of hostile, erratic, or coercive parenting on child adjustment (for a review, see Gecas \& Seff, 1990), we proposed a negative relationship between parental hostility, inconsistency, and rejection and subsequent flexible, involved adolescent problem-solving behavior. With regard to the influence of positive adolescent behavior on parents, earlier work indicates that socially skilled children elicit favorable responses from parents (Anderson, 1981; Werner \& Smith, 1992). Thus, the parents of an adolescent who initially approached disagreements openly, optimistically, and with a desire to overcome differences were expected to, over time, respond to their child with comparatively less hostility and rejection.

The third condition examined the reciprocal relationships among nurturant parenting and disruptive, inflexible adolescent problem-solving behavior. Drawing once again on prior research (Conger et al., 1992, 1993; Gecas \& Seff, 1990), we hypothesized that parents who use nurturant methods for guiding their child's behavior promote positive behavior in the child and thus negatively influence defensive, avoidant, or obdurate adolescent behavior over time. Also, recognizing that a difficult adolescent can exasperate even skillful parents, we hypothesized a negative relationship between disruptive, inflexible adolescent behavior and later parental nurturance.

Finally, the reciprocal relationships between nurturant childrearing practices and flexible, involved adolescent problem solving were estimated. Positive overall results were expected from these analyses. In comparison with other adolescents, those who received assertive, positive guidance from parents were expected to, over time, be more likely to take an active and cooperative approach to resolving differences (Conger et al., 1992, 1993; Gecas \& Seff, 1990). Also, an adolescent who willingly joined in the process of finding workable solutions to family problems was expected to reward parental behavior, thus promoting rela- tively greater nurturant parenting across time (Anderson, 1981; Werner \& Smith, 1992).

\section{Design Issues}

The design for the test of this conceptual model attempted to address the methodological challenges described earlier. Specifically, longitudinal data collected over three time points were used. Also, because the pertinent literature contains little consensus on the best time interval for measuring changes in parent-adolescent interactions, the study hypotheses were tested at two different measurement intervals. The first test involved a measurement interval of 2 years. This model suggests that change occurs slowly, as part of a gradual, long-term process. It is consistent with Patterson's (1982) thesis that coercive processes require thousands of daily transactions to change behavior. To examine the possibility that these interpersonal influences take less time to transpire, we tested a second model. This model involved 1-year time lags between measurement points. It is important to note that both of these models control for earlier behavior when predicting both parenting and adolescent behavior. Thus, as depicted in Figure 1, the cross-lagged paths from parenting practices to adolescent problem-solving behavior represent parental influence on changes in adolescent behavior. Likewise, the cross-lagged paths from adolescent behavior to parenting represent the adolescent's influence on changes in parenting practices.

The parents' behavior toward their child and the child's behavior toward the parents were measured with independent observers. That is, one set of observers viewed a videotaped family discussion task and assessed parenting behavior. A second set of independent observers viewed a second videotaped task, the parent-child problem-solving task, and assessed the adolescent's problem-solving behavior. Using independent observers in this way reduced the potential for inflated reciprocal associations (Bank et al., 1990; Lorenz et al., 1991). Finally, the hypothesized relationships were estimated via structural equation modeling techniques, which allowed simultaneous assessment of both stability and reciprocal influences in the proposed parentadolescent transactions. The Method section provides a more detailed description of the study design.

\section{Method}

\section{Sample}

The families in this study were participants in the Iowa Youth and Families Project. They were recruited through all 34 public and private schools with a seventh-grade class in selected communities in eight Iowa counties. Names and addresses of seventh-grade students and their parents were obtained from all schools in communities of 6,500 or less. After receiving a letter explaining the research project, families were contacted by telephone and asked to participate. About $78 \%$ of the eligible families agreed to take part in the study. Each participating family member was paid approximately $\$ 10$ per hour of participation.

When first interviewed in 1989 , the sample for these analyses consisted of 451 White, primarily lower-middle-class and middle-class families. Each family included two biological parents (average length of marriage $=17.9$ years), a seventh-grade target adolescent (mean age $=12.7$ years; 236 girls and 215 boys), and a male or female sibling. The age of the sibling varied, but all siblings were within 4 years of age, either older or younger, of the seventh grader. All families lived in 


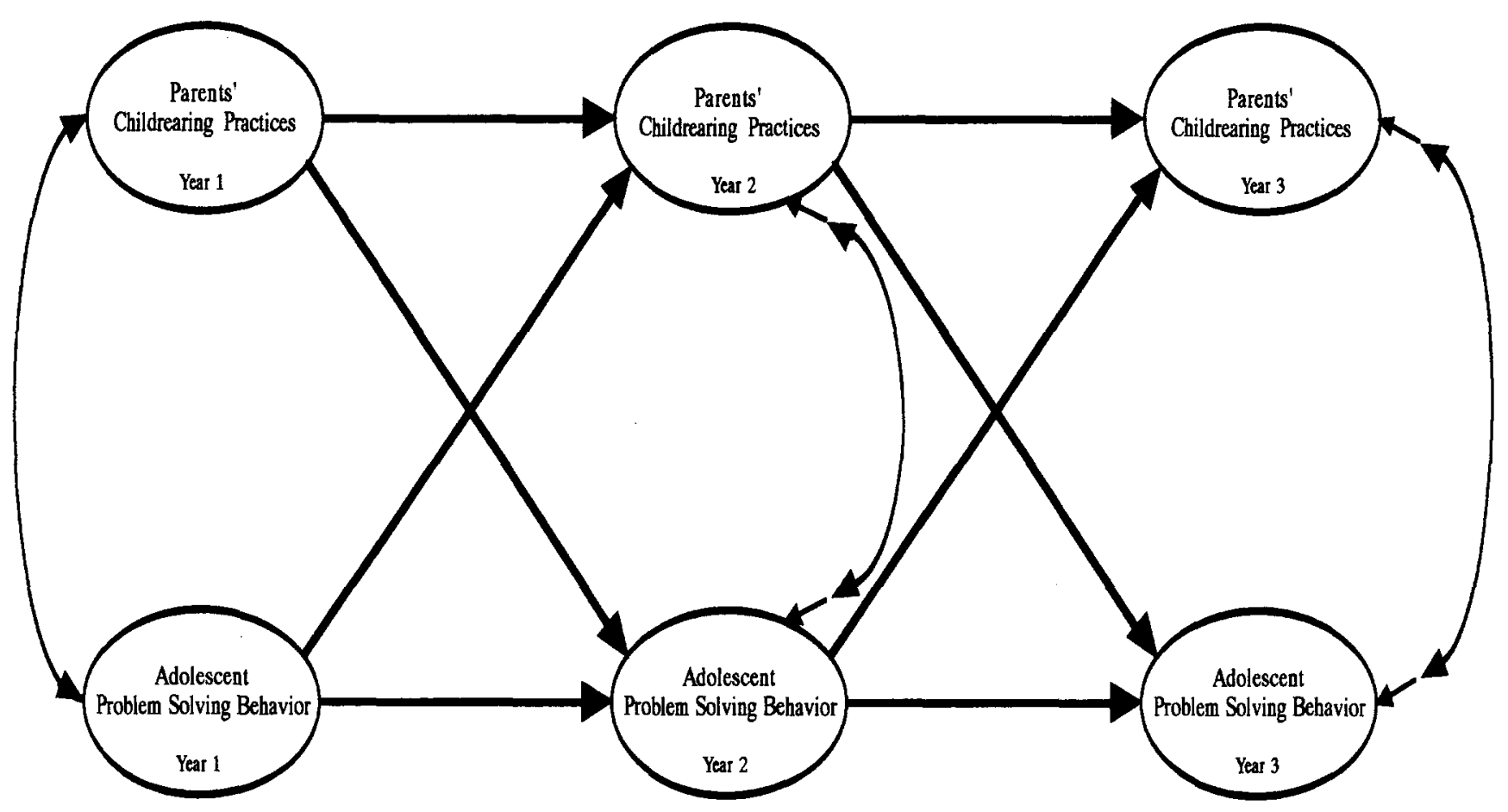

Figure 1. Conceptual model depicting the hypothesized associations among parents' child-rearing practices and adolescent problem-solving behavior.

small towns or the countryside. Specifically, $34 \%$ lived on a farm, $12 \%$ lived outside a town but not on a farm, and $54 \%$ lived in a town with a population of no greater than 6,500 . The average family size was 4.95 members, and the family median income for 1988 was $\$ 33,399$.

Participants were interviewed in 1989 (when the target adolescent was in seventh grade), 1990, and 1991. The retention rate for each year of data collection was about $95 \%$. However, over the course of the study, nine families experienced divorce or an older sibling left home to live elsewhere. To retain the complete family system, we dropped these families from the analyses. Another 23 families were lost as a result of missing data, and over the 2-year period, 44 families withdrew from the study. Thus, the final sample consisted of 375 families.

The families not included in the present investigation were, in most respects, similar to those who remained in the study. Differences in parents' age and education, however, did arise. Parents remaining in the study sample were, on average, older (mothers, $M=37.99$ years; fathers, $M=39.98$ years) than the missing or excluded parents (mothers, $M=$ 36.32 years; fathers, $M=38.51$ years). The study parents were also, on average, better educated (mothers, $M=13.39$ years; fathers, $M=$ 13.57 years) than the missing or excluded parents (mothers, $M=12.83$ years; fathers, $M=13.04$ years). In terms of income and all of the variables used in these analyses, however, no statistically significant differences were found between the sample families and the missing or excluded families.

\section{Procedure}

During each year of the study, families were visited twice in their home. During the first visit, each participating family member completed a set of questionnaires focusing on, among other issues, family member characteristics and patterns of family interaction. The second visit occurred within 2 weeks of the first. A trained interviewer began the second visit by asking both parents and the 2 children to complete a checklist designed to identify current disagreements or conflicts between the parents and children. Potential areas of disagreement included household chores, homework, transportation, and so forth. After completing the checklists, family members were asked to gather around a table for the videotaping of four different structured interaction tasks. Information gathered during the first two interaction tasks was used in the present study.

For the first interaction task (Task 1), family members were given a set of cards containing questions about their family life designed to elicit a wide range of parent-child interactions. As was the case in all four tasks, the interviewer explained the task procedures, completed a practice card with the family, and checked the video-recording equipment before leaving the room for another part of the house. The family spent a total of 35 min discussing the Task 1 cards. Data for the measures of parental child-rearing practices were collected from this first interaction task.

The problem-solving task (Task 2) began shortly after Task 1 and lasted $15 \mathrm{~min}$. During this task, parents and children discussed and attempted to resolve three problems identified on the previously completed checklists. Families were asked to first discuss the problem that created the most difficulties and disagreements between parents and children. They were told to go on to the second and third problems only after resolving the first problem. Data for the measures of adolescent problem-solving behavior were collected while the family addressed the first problem.

The videotaped family interactions were globally rated by trained observers who used the Iowa Family Interaction Rating Scales (Melby et al., 1989) to rate child-rearing and problem-solving behaviors. All video observers received $200 \mathrm{hr}$ ( $20 \mathrm{hr}$ per week for 10 weeks) of training before they began rating study videotapes. In addition, each observer was required to pass extensive written and observation tests before completing initial training. Scores of at least $90 \%$ correct were required on all written tests. Ninety percent agreement within one step 
of predetermined ratings and $70 \%$ perfect agreement with predetermined ratings were required on the observation tests. After completing the initial training, all observers received approximately $4 \mathrm{hr}$ of additional training each week to prevent "rater drift." As a means of assessing rater reliability, approximately $12 \%$ of all tasks in Year 1 and $25 \%$ of all tasks in Years 2 and 3 were randomly assigned to be rated by a second, independent rater. The primary and secondary ratings were then compared via intraclass correlations (Shrout \& Fleiss, 1979; Suen \& Ary, 1989). In general, the intraclass correlations for observer ratings ranged from .55 to .85 , a level of reliability considered acceptable for these types of data (Kenny, 1991; Mitchell, 1979). An observer rating manual with a complete description of all task procedures and all rating procedures, including definitions for all rating scales, is available from Martha A. Rueter.

\section{Measures}

This study operationalized two concepts: parents' child-rearing practices and adolescents' problem-solving behavior. In measuring parent and child behavior, several steps were taken to reduce method bias. First, child-rearing practices and adolescent behavior were measured during different observational tasks with independent observers. Second, all observation assignments were made randomly to guard against unrealistically inflated stability coefficients. Of course, as a result of random assignment, some overlap in family observation did occur. Over the investigation's three waves of data collection, approximately $8 \%$ of the families were viewed by the same observer in 2 or more years. Finally, observers were required to remain Task 1 raters or Task 2 raters throughout the investigation to reduce the possibility of overestimating crosslagged relationships. Three (of 37) observers did, however, switch from viewing Task 1 tapes throughout one study year to viewing Task 2 tapes in a subsequent year. Even with this switch, less than one half of $1 \%$ of families were viewed by the same observer across Tasks 1 and 2 .

Parents' child-rearing practices. Each parent's child-rearing practices were assessed in the study's 1 st, 2 nd, and 3rd years. The Task 1 observational raters viewed the general family interaction task and rated verbal and nonverbal parenting behaviors using a global rating scale that ranged from 1 (the behavior is not at all characteristic of the focal) to 5 (the behavior is very characteristic of the focal). Two latent constructs (harsh, inconsistent parenting and nurturant parenting) were created from the observed parental behaviors. Each of these constructs was measured with three indicators. Because later analyses indicated that mothers' and fathers' child-rearing scores related in the same fashion to adolescent behavior and were highly intercorrelated, the parents' scores were combined to create child-rearing scales summed across parent gender.

The first indicator of harsh, inconsistent parenting, hostility-coerciveness, combined two observational ratings. The first rating, hostility, assessed the extent to which each parent directed angry, critical, disapproving, or rejecting behavior toward the target adolescent. The angry coercion rating assessed the extent to which each parent used verbal or nonverbal threats or bullying to gain compliance from the target. Parents' scores for these observational measures were summed. Internal consistencies for the hostility-coerciveness indicator were .75 in Year 1, .78 in Year 2, and .80 in Year 3.

Inconsistent discipline was assessed via a single observational rating defined as the degree to which parents were inconsistent in applying or following through on reinforcing rules or standards of conduct. Correlations between the mothers' and the fathers' rates were .81 (Year 1) and .84 (Years 2 and 3 ). The two ratings were summed to create the indicator of inconsistent discipline.

A single observational rating, child monitoring, assessed the extent to which parents exhibited specific knowledge of the target's daily activities and the accuracy with which they tracked the target's behavior and social involvements. Correlations between the mothers' and fathers' ratings of child monitoring ranged from .60 (Years 1 and 3) to .67 (Year
2). After reverse coding of both ratings, the mothers' and fathers' ratings were summed to produce the measure of poor child monitoring.

The three indicators of nurturant parenting were designed to measure a range of possible approaches to gaining child compliance and developing a nurturant parent-child relationship. The warmth-supportiveness indicator was developed with four observational ratings. The first rating, communication, measured the parents' ability to state views, needs, and expectations clearly and understandably. Observers also rated assertiveness, the ability to address the child in a firm, straightforward manner. Behaviors measured as communication or as assertive could occur in response to child misbehavior or as an attempt to preclude misbehavior. Only behaviors made with neutral or positive affect were rated as communication or as assertive. The third measure, warmth, assessed parents' verbal and nonverbal expressions of caring, warmth, and support toward the target adolescent. Listener responsiveness, the final measure of warmth-supportiveness, assessed the parents' verbal and nonverbal indications of attentiveness to the target's verbalizations. Both parents' scores on these four measures were summed, creating an eight-item scale ( $\alpha=.82$, Years 1 and 3; $\alpha=.85$, Year 2).

Observers assessed parental rewarding behavior using a single observational rating. This rating measured the degree to which parents praised, rewarded, or otherwise positively responded to the target when he or she met their expectations and standards. Correlations between the mothers' and fathers' ratings were .54 in Year 1, .66 in Year 2, and .61 in Year 3 . The two ratings were summed to produce the measure of parental rewarding behavior.

The third indicator of nurturant parenting, inductive reasoning, was defined as the extent to which a parent gained adolescent compliance by using explanations or reasoning, by clarifying the consequences of the target's behavior, or by encouraging the target to consider the feelings of others. Observers rated each parent on inductive reasoning using a single observational rating. The correlations between the mothers' and the fathers' ratings were .50 (Year 1), .58 (Year 2), and .45 (Year 3 ). The two scores were summed to create the measure of parental inductive reasoning.

Adolescent problem solving. During the $1 \mathrm{st}, 2 \mathrm{nd}$, and $3 \mathrm{rd}$ study years, Task 2 observational raters viewed the family problem-solving task (Task 2) and rated the adolescent's problem-solving behavior. These observers used a global rating scale that ranged from 1 (the behavior is not at all characteristic of the focal) to 5 (the behavior is very characteristic of the focal) to rate the adolescent's verbal and nonverbal behavior. The adolescents' behaviors were formed into two latent constructs, disruptive, inflexible problem solving and involved, flexible problem solving. Each construct was measured with three indicators. Previous research has demonstrated the usefulness of these two sets of indicators in predicting family reports of successful and unsuccessful attempts to solve salient family problems (Rueter \& Conger, 1995a, 1995b).

The first indicator of disruptive, inflexible problem solving, disruption, included behaviors such as drawing the family off task and halting problem solving by refusing to continue with the process. Task 2 observers used a single rating to assess the extent to which the adolescent displayed these behaviors. Denial, the second indicator of disruptive, inflexible problem solving, was defined as the extent to which the adolescent avoided or refused to take responsibility for problem resolution by actively rejecting the existence of or personal responsibility for the problem or by casting blame for the problem onto other family members. Each adolescent received three scores for denial, one for the amount of denial directed toward each of the three other family members. Internal consistencies for the summed scales were .73 (Year 1) and .79 (Years 2 and 3 ). Adolescents exhibiting insensitivity, the third indicator of disruptive, inflexible problem solving, were impatient, self-centered, or unwilling to comply with the wishes of others during the problemsolving discussion. Observers rated each adolescent on the level of insensitivity he or she directed toward the three other family members. The resulting scores were summed to create the three-item indicator (Year $1: \alpha=.90$; Years 2 and 3: $\alpha=.88$ ). 
Facilitative engagement, the first indicator of flexible, involved problem solving, was measured using a single observational rating. This rating assessed the extent to which adolescents helped to describe or clarify the problem, solicited the views of other family members, and provided summaries of progress toward resolution of the problem. Two ratings were summed to create the next indicator, solution generation. The first rating, solution number, represented the observer's assessment of the number of solutions offered by the adolescent $(1=$ no solutions, $5=$ four or more solutions). The second rating assessed the extent to which the adolescent proposed reasonable, realistic, beneficial, achievable, and specifically stated solutions. The ratings for solution quality ranged from 1 (no solutions offered) to 5 (at least one very high quality solution was suggested). Correlations between solution number and solution quality ratings were .66 (Year 1), .73 (Year 2), and .79 (Year 3 ). The final indicator of flexible, involved problem solving, sensitivity, was defined as the adolescent's ability to maintain a patient and cooperative manner during problem solving. Raters assessed the adolescent's sensitivity toward the three other family members. The three ratings were summed to create the measure of sensitivity; alpha reliability coefficients were .87 in the 1 st year, .77 in the 2 nd year, and .88 in the $3 \mathrm{rd}$ year.

\section{Analytic Plan}

Two sets of nested model comparisons were used to test the conceptual model (Figure 1). Both sets of comparisons used maximum-likelihood estimates of the hypothesized associations obtained through structural equation modeling procedures (Jöreskog \& Sörbom, 1989b). The first set of comparisons tested the associations between parental and adolescent behavior using a 2-year measurement interval. The second set of comparisons tested the same associations using the 1-year measurement intervals. As shown in Figure 1, the hypothesized reciprocal relationships were estimated controlling for both autoregressive effects and crosssectional covariances. Although not depicted, the loadings for parallel indicators were constrained to be equal. The resulting factor loadings were all statistically significant and averaged .60 , with a range from .24 to .89 . In addition, the residual errors of parallel indicators were allowed to correlate in all analyses. For example, in the 2-year time lag analyses, we correlated the residual errors between hostility-coerciveness in Year 1 and hostility-coerciveness in Year 3. Overall, the correlations among residual errors ranged from $-.15(p<.05)$ to $.26(p<.05)$.

Each set of comparisons proceeded in a series of steps. Step 1 tested the reciprocal model. As depicted in Figure 1, this model specified the autoregressive effects, the influence from parental behavior to adolescent behavior, and the influence from adolescent behavior to parental behavior. In Step 2, we analyzed the base model. This model specified only the autoregressive effects, hypothesizing that cross-lagged associations do not exist. The base model and the reciprocal model are directly comparable because the base model is nested within the reciprocal model. The comparison is made by subtracting the chi-square value produced by the reciprocal model from the chi-square value produced by the base model. If the resulting chi-square value is statistically significant, the finding indicates that the reciprocal model best represents the relationships in the data. A nonsignificant change in the chi-square value indicates that the more parsimonious, base model fits the data best.

In the third step, we analyzed a model that specified the autoregressive effects and the unidirectional influence of parental behavior on adolescent behavior. This third model is also nested within the reciprocal model and thus comparable to it. If subtracting the chi-square value produced by the reciprocal model from the chi-square value produced by this third model produces a statistically significant result, the reciprocal model is accepted as best representing the data. A nonsignificant result indicates that the unidirectional model best fits the data.

The final step analyzed a model specifying the autoregressive effects and the unidirectional influence from adolescent behavior to parental behavior. Like the third model, this final model is nested within the reciprocal model, and, as just described, the chi-square value produced by it was compared with that of the reciprocal model to determine which model best represented the data.

\section{Results}

Before beginning the analyses, we performed a number of tests to ensure adherence to the underlying assumptions of structural equation modeling. Initially, we regressed each dependent variable on each respective independent variable, entering a quadratic and cubic term into each analysis to test for nonlinear associations. In each case, we found only linear associations. Next we checked for the presence of outliers in the study sample. Visual inspection of the data suggested the absence of outliers for each study variable. However, to further assure ourselves of the absence of outliers, we ran the initial analyses both with and without the five cases showing the largest values on Mardia's coefficient (Bentler, 1995). Comparison of these initial results showed little or no differences in model parameters. Therefore, we ran further analyses using the entire sample. Finally, measures of multivariate kurtosis and skewness indicated significant departures from multivariate normality in the study sample; therefore, the data were normalized using the Blom normalizing transformation (SPSS, Inc., 1994). Having normalized the data, we compared the results from analyses using the normalized data with those from analyses using the original, nonnormalized data. Although we found only negligible or no differences in model parameters, we chose to guard against possible violation of structural equation modeling assumptions by using the normalized data in the remainder of the analyses. ${ }^{1}$

After completing these initial tests, we analyzed each theoretical model separating mothers with a daughter from those with a son and fathers with a daughter from those with a son. Comparisons using the LISREL multiple group comparison option (Jöreskog \& Sörbom, 1989a) showed no statistically significant differences between the mothers' and fathers' 2-year interval models or between the girls' and boys' 2-year interval models. This was also the case for the 1-year time interval models. Therefore, the results presented here were obtained by first summing the mothers' and fathers' child-rearing measures and then performing the analyses using the combined sample of boys and girls. Table 1 presents the nonnormalized means and standard deviations for all resulting study indicators. ${ }^{2}$ The 2-year interval models used the indicators from Year 1 and Year 3. The 1-year interval models used the indicators from all 3 years.

\section{Model Testing: Two-Year Measurement Interval}

Following the analytic plan described earlier, the testing of the interrelationships between harsh, inconsistent parenting and disruptive, inflexible adolescent problem solving began with

\footnotetext{
${ }^{1}$ Results of these initial tests are available from Martha A. Rueter

2 The matrix of correlations among the indicators for these analyses included 36 variables ( 9 indicators each for harsh-inconsistent parenting, nurturant parenting, disruptive-inflexible problem solving, and flexible-involved problem solving). Because a matrix of this size is large and cumbersome, it is not reproduced here. However, the correlations among the study indicators are available on request from Martha A. Rueter
} 
Table 1

Means and Standard Deviations for the Study Indicators

\begin{tabular}{lcc}
\hline \multicolumn{1}{c}{ Year and indicator } & $M$ & $S D$ \\
\hline \multicolumn{1}{c}{ Harsh-inconsistent parenting } \\
Year 1 & & \\
Hostility-coerciveness & 6.74 & 2.40 \\
Inconsistent discipline & 4.93 & 1.71 \\
Poor child monitoring & 4.82 & 1.34 \\
Year 2 & & \\
Hostility-coerciveness & 7.54 & 2.72 \\
Inconsistent discipline & 4.09 & 1.94 \\
Poor child monitoring & 4.40 & 1.50 \\
Year 3 & & \\
Hostility-coerciveness & 8.09 & 3.10 \\
Inconsistent discipline & 4.59 & 2.04 \\
Poor child monitoring & 4.18 & 1.47 \\
\hline
\end{tabular}

Nurturant parenting

Year 1

\begin{tabular}{lrl} 
Warmth-supportiveness & 26.83 & 4.58 \\
Rewarding & 5.86 & 1.56 \\
Inductive reasoning & 4.19 & 1.48 \\
Year 2 & & \\
Warmth-supportiveness & 25.26 & 4.90 \\
Rewarding & 6.18 & 1.64 \\
Inductive reasoning & 4.12 & 1.54 \\
Year 3 & & \\
Warmth-supportiveness & 22.85 & 4.51 \\
Rewarding & 5.55 & 1.66 \\
Inductive reasoning & 4.01 & 1.35 \\
\hline
\end{tabular}

Disruptive-inflexible adolescent problem solving

Year 1

$\begin{array}{lll}\text { Disruption } & 2.46 & 1.22 \\ \text { Denial } & 5.46 & 2.25 \\ \text { Insensitivity } & 7.95 & 3.07 \\ \text { Year 2 } & & \\ \text { Disruption } & 2.71 & 1.23 \\ \text { Denial } & 5.33 & 2.30 \\ \text { Insensitivity } & 8.08 & 3.05 \\ \text { Year 3 } & & \\ \text { Disruption } & 2.88 & 1.25 \\ \text { Denial } & 6.48 & 2.91 \\ \text { Insensitivity } & 8.70 & 3.28\end{array}$

Flexible-involved adolescent problem solving

Year 1

\begin{tabular}{lll} 
Facilitative engagement & 1.97 & 0.50 \\
Solution generation & 4.46 & 2.16 \\
Sensitivity & 6.34 & 1.60 \\
Year 2 & & \\
Facilitative engagement & 2.05 & 0.50 \\
Solution generation & 4.37 & 2.08 \\
Sensitivity & 6.24 & 1.48 \\
ear 3 & & \\
Facilitative engagement & 1.86 & 0.52 \\
Solution generation & 4.00 & 2.10 \\
Sensitivity & 5.81 & 1.57 \\
\hline
\end{tabular}

nested model comparisons. These comparisons indicated that the reciprocal model produced the best overall model fit. Specifically, when compared with the base model's chi-square value and other fit indices, $\chi^{2}(48, N=375)=104.47$, standardized root-mean-square residual (SRMR) $=.054$, goodness-of-fit in$\operatorname{dex}(\mathrm{GFI})=.96$, comparative fix index $(\mathrm{CFI})=.95$, Hoelter's critical $N(\mathrm{CN})=263$, the reciprocal model produced a statistically significant improvement in model fit, $\Delta \chi^{2}(2, N=375)$ $=19.21, p<.05$ ( see Table 2 for the reciprocal model fit indices). The reciprocal model also represented the data better than the model specifying only a unidirectional effect from parents to the adolescent, $\Delta \chi^{2}(1, N=375)=5.97, p<.05$, and better than the model specifying only a unidirectional effect from the adolescent to the parents, $\Delta \chi^{2}(1, N=375)=10.03$. $p<.05$. These results suggest a reciprocal process whereby, over time, harsh, inconsistent parenting influences adolescent problem-solving behavior and adolescent behavior influences parenting behavior.

The second set of 2-year time lag analyses tested the interrelationships between harsh, inconsistent child rearing and flexible, involved adolescent problem solving. These nested model comparisons suggested the presence of unidirectional effects from parents to adolescent behavior. In comparison with the base model, $\chi^{2}(48, N=375)=117.37$, SRMR $=.070, \mathrm{GFI}=$ $.95, \mathrm{CFI}=.84, \mathrm{CN}=238$, the reciprocal model produced a significantly better fit with the data, $\Delta \chi^{2}(2, N=375)=20.90$, $p<.05$. The reciprocal model also fit the data better than the model that specified a unidirectional influence from adolescents to parents, $\Delta \chi^{2}(1, N=375)=20.49, p<.05$. However, the reciprocal model did not fit the data better than the model specifying a unidirectional influence from harsh, inconsistent parenting and flexible, involved adolescent behavior. Thus, this more parsimonious unidirectional model best represents these data.

The next set of analyses tested the interrelationships between nurturant parenting and disruptive, inflexible adolescent problem solving. As with the first set of 2 -year interval analyses, this third set of results supports the presence of reciprocal parentadolescent interactions. In comparison with the base model's fit indices, $\chi^{2}(48, N=375)=71.78$, SRMR $=.064$, GFI $=$ $.97, \mathrm{CFI}=.98, \mathrm{CN}=383$, the reciprocal model produced a significantly better fit, $\Delta \chi^{2}(2, N=375)=22.52, p<.05$. The reciprocal model also fit the data better than the two unidirectional models: parents to adolescent, $\Delta \chi^{2}(1, N=375)=9.04$, $p<.05$, and adolescent to parents, $\Delta \chi^{2}(1, N=375)=12.89$, $p<.05$.

The final set of 2-year interval analyses suggested the presence of a unidirectional effect from nurturant parenting to flexible, involved adolescent behavior. The results of the nested model comparisons showed that, as compared with the base model, $\chi^{2}(48, N=375)=92.25$, SRMR $=.074$, GFI $=$ $.96, \mathrm{CFI}=.94, \mathrm{CN}=298$, the reciprocal model fit the data significantly better, $\Delta \chi^{2}(2, N=375)=11.14, p<.05$. It also fit the data better than the unidirectional model specifying an influence from adolescents to parents, $\Delta \chi^{2}(1, N=375)=$ $11.05, p<.05$. The reciprocal model did not, however, represent the data better than the model specifying a unidirectional influence from nurturant parenting and flexible, involved adolescent behavior.

Model comparisons indicate which models best fit the data, but they provide little indication of the magnitude of the relationships among the latent constructs. This information is shown in Table 2, which presents the maximum-likelihood estimates of the structural coefficients and the amount of variance explained by the specified relationships. The first and third columns of Table 2 present the estimates of the associations among 
Table 2

Standardized Maximum-Likelihood Estimates of the Structural Coefficients for the Two-Year Time Interval Reciprocal Models

\begin{tabular}{|c|c|c|c|c|}
\hline \multirow[b]{2}{*}{ Structural parameter } & \multicolumn{4}{|c|}{ Analytic model } \\
\hline & $\begin{array}{c}\text { Harsh-inconsistent parenting } \\
\text { and disruptive-inflexible } \\
\text { adolescent } \\
\text { problem solving }\end{array}$ & $\begin{array}{l}\text { Harsh-inconsistent parenting } \\
\text { and fiexible-involved } \\
\text { adolescent } \\
\text { problem solving }\end{array}$ & $\begin{array}{l}\text { Nurturant parenting and } \\
\text { disruptive-inflexible } \\
\text { adolescent } \\
\text { problem solving }\end{array}$ & $\begin{array}{l}\text { Nurturant parenting and } \\
\text { flexible-involved } \\
\text { adolescent } \\
\text { problem solving }\end{array}$ \\
\hline \multicolumn{5}{|l|}{ Autoregressive coefficients } \\
\hline Parents: Year 1 to Year 3 & $.53 *$ & $.58^{*}$ & $.56^{*}$ & $.60^{*}$ \\
\hline Adolescents: Year 1 to Year 3 & $.43 *$ & $.36^{*}$ & $.52 *$ & $.33 *$ \\
\hline \multicolumn{5}{|l|}{ Cross-lagged coefficients } \\
\hline Parents to adolescents & $.27 *$ & $-.19 *$ & $-.21 *$ & $.28 *$ \\
\hline Adolescents to parents & $.24 *$ & -.01 & $-.18 *$ & -.02 \\
\hline \multicolumn{5}{|l|}{ Cross-sectional covariances } \\
\hline Year 1 & $.50^{*}$ & .04 & $-.22 *$ & .08 \\
\hline Year 3 & $.34 *$ & $-.16^{*}$ & $-.12 *$ & $.11^{*}$ \\
\hline \multicolumn{5}{|l|}{ Explained variance } \\
\hline \multicolumn{5}{|l|}{ Adolescent behavior, Year 3} \\
\hline Total & $.38 *$ & $.16^{*}$ & $.37 *$ & $.20^{*}$ \\
\hline Parents' effect, Year 1 & $.06^{*}$ & $.04 *$ & $.05^{*}$ & $.05^{*}$ \\
\hline \multicolumn{5}{|l|}{ Parental behavior, Year 3} \\
\hline Total & $.47 *$ & $.34 *$ & $.39 *$ & $.36^{*}$ \\
\hline Adolescents' effect, Year 1 & $.04^{*}$ & .01 & $.03 *$ & .02 \\
\hline$\chi^{2}$ & 85.26 & 96.47 & 49.26 & 81.11 \\
\hline$\hat{d f}$ & 46 & 46 & 46 & 46 \\
\hline SRMR & .046 & .065 & .037 & .063 \\
\hline GFI & .96 & .96 & .98 & .96 \\
\hline CFI & .96 & .88 & 1.00 & .95 \\
\hline $\mathrm{CN}$ & $312^{\circ}$ & 276 & 539 & 328 \\
\hline
\end{tabular}

Note. $\quad$ SRMR = standardized root-mean-square residual; GFI = goodness-of-fit index; $\mathrm{CFI}=$ comparative fit index; $\mathrm{CN}=\mathrm{Hoelter}$ 's critical $N$. $* p<.05$.

child-rearing practices and disruptive, inflexible adolescent problem-solving behavior. Both columns show robust and balanced autoregressive coefficients indicating that both forms of parental behavior and disruptive, inflexible adolescent behavior were quite stable over time. Over and above the autoregressive relationships, these analyses produced statistically significant cross-lagged relationships that accounted for a significant amount of explained variance. For example, looking at the first column of Table 2, harsh-inconsistent parenting significantly influenced changes in disruptive-inflexible adolescent problemsolving behavior $\left(\beta=.27, R^{2}=.06, p<.05\right)$, and disruptive adolescent behavior influenced changes in harsh-inconsistent parenting $\left(\beta=.24, R^{2}=.04, p<.05\right)$. The cross-lagged results presented in the third column are also statistically significant (nurturant parenting to disruptive adolescent behavior, $\beta=$ $-.21, R^{2}=.05, p<.05$, and disruptive adolescent behavior to nurturant parenting, $\left.\beta=-.18, R^{2}=.03, p<.05\right)$. Thus, these results, along with the model comparisons, support the presence of reciprocal influences between child-rearing practices and disruptive, inflexible adolescent problem-solving behavior.

The second and fourth columns in Table 2 present findings that are also consistent with the model comparisons. The second column shows results indicating a unidirectional, negative influence from harsh, inconsistent child-rearing practices to flexible, involved adolescent problem solving $\left(\beta=-.19, R^{2}=\right.$ $.04, p<.05$ ), with no statistically significant influence from adolescent behavior to parenting. Likewise, the last column of Table 2 shows a positive association between nurturant, involved parenting and flexible, involved adolescent problem solving ( $\beta$ $\left.=.28, R^{2}=.05, p<.05\right)$ but no statistically significant influence from flexible, involved adolescent behavior to parental behavior.

These unidirectional findings require cautious interpretation. Both sets of analyses produced unequal stability coefficients (second column: harsh-inconsistent parenting, $\beta=.58, p<$ .05 , and flexible-involved adolescent behavior, $\beta=.36, p<$ .05 ; fourth column: nurturant child-rearing practices, $\beta=.60$, $p<.05$, and flexible-involved adolescent behavior, $\beta=.33$, $p<.05$ ). Unidirectional effects can be due, in large part, to imbalances in stability (autoregressive) coefficients and thus may misrepresent relationships among the data (Cook \& Campbell, 1979; Dwyer, 1983; Lorenz et al., 1995). Alternatively, unidirectional cross-lagged effects may accurately represent the data if one construct changes more easily than the other (Davis, 1985; Lorenz et al., 1995). Indeed, earlier research has shown that positive behavior is less stable than negative behavior (Conger, Brainerd, Birch, Friedberg, \& Navarro, 1986), and, although not originally hypothesized in the present case, one might expect an adolescent's ability to remain on task, generate realistic solutions, and patiently engage in a problem-solving task to be more mutable than his or her parents' child-rearing practices.

The correlations among the model constructs provide additional empirical evidence for evaluating these unidirectional results. For example, the cross-lagged correlations between Year 1 harsh, inconsistent child-rearing practices and Year 3 flexible, involved adolescent behavior $(r=-.17)$ and between Year 1 flexible, involved adolescent behavior and Year 3 harsh, inconsistent parenting $(r=.01)$ closely resemble their respective 
path coefficients ( $\beta=-.19$ and $\beta=-.01$ ). The cross-lagged correlations between Year 1 nurturant parenting and Year 3 flexible, involved adolescent behavior $(r=.31)$ and between Year 1 flexible, involved adolescent behavior and Year 3 nurturant child-rearing practices $(r=.03)$ also closely match their respective path coefficients ( $\beta=.28$ and $\beta=-.02$ ). These results allow us to conclude that the unidirectional effects are not simply artifacts of differential stabilities; rather, they accurately represent relationships among the data.

\section{Model Testing: One-Year Measurement Interval}

As noted earlier, the appropriate time lag for measuring changes in parent-adolescent interactions is yet to be determined. Furthermore, earlier research demonstrates that one might obtain different patterns of association among study constructs at different measurement intervals (Sher et al., 1996). To evaluate the possibility that a shorter time between measurement points might produce different results, we reexamined the study hypotheses using a 1-year measurement interval.

As with the 2-year analyses, the tests of the 1-year models began with nested model comparisons. These comparisons produced the same pattern of associations found for the 2-year interval models. That is, in comparison with the base model test, $\chi^{2}(118, N=375)=200.44$, SRMR $=.054, \mathrm{GFI}=.94$, $\mathrm{CFI}=.96, \mathrm{CN}=281$, of the interrelationships between harsh, inconsistent parenting and disruptive, inflexible adolescent problem-solving behavior, the reciprocal model, $\Delta \chi^{2}(4, N=375)$ $=20.90, p<.05$ (see Table 3 for the reciprocal model fit indices), better fit the data. The reciprocal model also fit the data better than both unidirectional models: parents to adolescent, $\Delta \chi^{2}(2, N=375)=10.80, p<.05$, and adolescent to parents, $\Delta \chi^{2}(2, N=375)=15.33, p<.05$. The test of interrelationships between nurturant parenting and disruptive, inflexible adolescent behavior also produced a reciprocal model that represented the data better than the base model, $\chi^{2}(118, N=375)$ $=158.26, \mathrm{SRMR}=.067, \mathrm{GFI}=.95, \mathrm{CFI}=.98, \mathrm{CN}=355$, $\Delta \chi^{2}(4, N=375)=14.59, p<.05$, and better than the unidirectional models: parents to adolescent, $\Delta \chi^{2}(2, N=375)=7.94$, $p<.05$, and adolescent to parents, $\Delta \chi^{2}(2, N=375)=7.06$, $p<.05$. Thus, when the 1-year interval analyses involved testing associations between parenting and disruptive, inflexible adolescent behavior, the results suggested the presence of reciprocal interactions.

In tests of the 1-year interrelationships between parenting and flexible, involved adolescent behavior, the unidirectional, parent-effects models best represented the data. The first set of tests analyzed the associations between harsh, inconsistent parenting and flexible, involved adolescent behavior. Computergenerated modification indices suggested adding one further set of correlated errors to these analyses (Year 2 adolescent sensitivity with Year 2 parental hostility-coerciveness). The resulting reciprocal model fit the data significantly better than the base model, $\chi^{2}(117, N=375)=194.71$, SRMR $=.074, \mathrm{GFI}=$ $.94, \mathrm{CFI}=.91, \mathrm{CN}=287, \Delta \chi^{2}(4, N=375)=12.38, p$ $<.05$, and better than the unidirectional model specifying an influence from adolescent to parents, $\Delta \chi^{2}(2, N=375)=10.08$, $p<.05$. The reciprocal model did not represent the data better than the model specifying a unidirectional effect from parents to the adolescent. Similarly, in comparison with the base model test, $\chi^{2}(118, N=375)=190.24$, SRMR $=.083, \mathrm{GFI}=.95$, $\mathrm{CFI}=.94, \mathrm{CN}=296$, of the associations between nurturant parenting and flexible, involved adolescent behavior, the reciprocal model was a significant improvement, $\Delta \chi^{2}(4, N=375)=$ $22.47, p<.05$. The reciprocal model also represented that data significantly better than the model specifying a unidirectional effect from adolescent to parents, $\Delta \chi^{2}(2, N=375)=19.26$, $p<.05$, but not better than the model specifying a unidirectional effect from parents to adolescent.

Table 3 presents the maximum-likelihood estimates of the structural coefficients and lists the amounts of explained variance for the 1-year interval analyses. Consistent with the model comparisons, the 1-year associations among parenting and flexible, involved adolescent problem-solving behavior showed only unidirectional, parental effects. ${ }^{3}$ On the other hand, the analyses involving disruptive, inflexible adolescent behavior showed effects from parents to adolescents as well as from adolescents to parents. For example, the results presented in the first column of Table 3 show a marginal influence from Year 1 disruptive adolescent behavior to changes in Year 2 harsh, inconsistent child-rearing practices $\left(\beta=.15, R^{2}=.00, p<.10\right)$, whereas, from Year 2 to Year 3, parenting behavior significantly influenced changes in adolescent behavior $\left(\beta=.30, R^{2}=.04, p<\right.$ $.05)$. Turning to the third column, the results suggest the presence of a reciprocal parent-adolescent effect between Years 1 and 2. However, from Year 2 to Year 3, the results show a unidirectional effect from nurturant parenting to disruptive, inflexible adolescent behavior $\left(\beta=-.11, R^{2}=.02, p<.05\right){ }^{4}$

\footnotetext{
${ }^{3}$ As with the 2-year interval analyses, these results also show less stability in effective adolescent problem-solving behavior than in parental behavior, and, as described earlier, they must be interpreted with caution. Concordance between the construct correlations and the model coefficients, however, supports the model findings. For example, the cross-lagged correlations from harsh, inconsistent child-rearing practices to flexible, involved adolescent behavior $(r=-.16$ for Year 1 parenting, $r=-.23$ for Year 2 parenting ) and from adolescent behavior to parental behavior ( $r=-.01$ for Year 1 adolescent behavior, $r=-.01$ for Year 2 adolescent behavior) were similar to their respective path coefficients. Also, the cross-lagged correlations from nurturant, involved parenting to flexible, involved adolescent behavior $(r=.20$ for Year 1 parenting, $r=.38$ for Year 2 parenting) and from adolescent behavior to parental behavior ( $r=.11$ for Year 1 adolescent behavior, $r=.10$ for Year 2 adolescent behavior) resembled their respective path coefficients.

${ }^{4}$ In response to one reviewer's suggestion that additional exogenous factors could account for the associations found in this study, we performed an additional set of analyses. The suggested exogenous predictors included family socioeconomic status (SES), the stability of the marriage, and adolescents' delinquent peer associations, all of which have been associated with parenting and with child behavior (cf. Conger \& Elder, 1994; Reid \& Crisafulli, 1990; Thornberry, Lizotte, Krohn, Farnworth, \& Jang, 1994). To perform the additional analyses, we first reanalyzed the 1-year measurement interval and 2-year measurement interval models after adding family SES as an exogenous predictor. Next, we reanalyzed the 1-year and 2-year models after adding marital stability as the exogenous predictor. Finally, we reanalyzed all models after adding delinquent peer associations as the predictor. Having done this, we found that, with one exception, the pattern of associations between parental and adolescent behavior remained unchanged over and above the influence of the exogenous predictors. The one exception occurred in the SES 2year measurement interval analyses. After SES had been controlled, the relationship between Year 1 harsh-inconsistent parenting and Year 3 flexible-involved adolescent problem-solving behavior was no longer
} 
Table 3

Standardized Maximum-Likelihood Estimates of the Structural Coefficients for the One-Year Time Interval Reciprocal Models

\begin{tabular}{|c|c|c|c|c|}
\hline \multirow[b]{2}{*}{ Structural parameter } & \multicolumn{4}{|c|}{ Analytic model } \\
\hline & $\begin{array}{c}\text { Harsh-inconsistent parenting } \\
\text { and disruptive-inflexible } \\
\text { adolescent } \\
\text { problem solving }\end{array}$ & $\begin{array}{l}\text { Harsh-inconsistent parenting } \\
\text { and flexible-involved } \\
\text { adolescent } \\
\text { problem solving }\end{array}$ & $\begin{array}{l}\text { Nurturant parenting and } \\
\text { disruptive-inflexible } \\
\text { adolescent } \\
\text { problem solving }\end{array}$ & $\begin{array}{l}\text { Nurturant parenting and } \\
\text { flexible-involved } \\
\text { adolescent } \\
\text { problem solving }\end{array}$ \\
\hline \multicolumn{5}{|l|}{ Autoregressive coefficients } \\
\hline \multicolumn{5}{|l|}{ Parents } \\
\hline Year 1 to Year 2 & $.70^{*}$ & $.70^{*}$ & $.62 *$ & $.65^{*}$ \\
\hline Year 2 to Year 3 & $.86^{*}$ & $.91 *$ & $.75 *$ & $.79 *$ \\
\hline \multicolumn{5}{|l|}{ Adolescents } \\
\hline Year 1 to Year 2 & $.60^{*}$ & $.40 *$ & $.64 *$ & $.36^{*}$ \\
\hline Year 2 to Year 3 & $.49 *$ & $.53 *$ & $.64 *$ & $.49 *$ \\
\hline \multicolumn{5}{|l|}{ Cross-lagged coefficients } \\
\hline \multicolumn{5}{|l|}{ Parents to adolescents } \\
\hline Year 1 to Year 2 & .12 & $-.20 *$ & $-.10^{*}$ & $.19^{*}$ \\
\hline Year 2 to Year 3 & $.30^{*}$ & $-.16^{*}$ & $-.11 *$ & $.28 *$ \\
\hline \multicolumn{5}{|l|}{ Adolescents to parents } \\
\hline Year 1 to Year 2 & .15 & -.07 & $-.14 *$ & .10 \\
\hline Year 2 to Year 3 & .08 & .10 & -.07 & -.06 \\
\hline \multicolumn{5}{|l|}{ Cross-sectional covariances } \\
\hline Year 1 & $.50 *$ & .09 & $-.22 *$ & .02 \\
\hline Year 2 & $.22 *$ & .02 & $-.15^{*}$ & .01 \\
\hline Year 3 & $.17^{*}$ & -.10 & -.06 & -.05 \\
\hline \multicolumn{5}{|l|}{ Explained variance } \\
\hline \multicolumn{5}{|l|}{ Adolescent behavior, Year 2} \\
\hline Total & $.44 *$ & $.19^{*}$ & $.45^{*}$ & $.17^{*}$ \\
\hline Parents' effect, Year 1 & .00 & $.05 *$ & $.03 *$ & $.02 *$ \\
\hline \multicolumn{5}{|l|}{ Adolescent behavior, Year 3} \\
\hline Total & $.51 *$ & $.34 *$ & $.48^{*}$ & $.37 *$ \\
\hline Parents' effect, Year 2 & $.04 *$ & $.03 *$ & $.02 *$ & $.03 *$ \\
\hline \multicolumn{5}{|l|}{ Parental behavior, Year 2} \\
\hline Total & $.62 *$ & $.49 *$ & $.44 *$ & $.43 *$ \\
\hline Adolescents' effect, Year 1 & .00 & .02 & $.03 *$ & .03 \\
\hline \multicolumn{5}{|l|}{ Parental behavior, Year 3} \\
\hline Total & $.82 *$ & $.82 *$ & $.60^{*}$ & $.61^{*}$ \\
\hline Adolescents' effect, Year 2 & .00 & .03 & .01 & .03 \\
\hline$\chi^{2}$ & 179.54 & 182.33 & 143.67 & 167.77 \\
\hline$\hat{d f}$ & 114 & $113^{\mathrm{a}}$ & 114 & 114 \\
\hline SRMR & .046 & .069 & .046 & .067 \\
\hline GFI & .95 & .95 & .96 & .95 \\
\hline $\mathrm{CFI}$ & .97 & .92 & .99 & .96 \\
\hline $\mathrm{CN}$ & 304 & 297 & 380 & 325 \\
\hline
\end{tabular}

Note. SRMR = standardized root-mean-square residual; GFI = goodness-of-fit index; CFI $=$ comparative fit index; CN $=$ Hoelter's critical $N$.

${ }^{a}$ Modification indices suggested the addition of correlated residual errors between Year 2 adolescent sensitivity and Year 2 parental hostilitycoerciveness. Therefore, these results have one less degree of freedom than the other one-year interval models.

$* p<.05$.

\section{Discussion}

In this investigation, we examined bidirectional parent-child interactions focusing specifically on the interplay between certain child-rearing strategies and adolescent problem-solving skills. This focus on adolescence and the development of problem-solving skills is significant in at least two ways. First, several theories (e.g., Bell \& Harper, 1977; Conger \& Simons, 1997; Patterson, 1982; Sameroff, 1975; Thornberry, 1987) propose reciprocal parent-child influences, but very little empirical

statistically significant. Overall, we concluded that the hypothesized relationships remained robust even after controlling for specific exogenous predictors. evidence exists to support these theories for parent-adolescent interactions. Second, adolescence is an important period for learning effective interpersonal problem-solving skills (Hauser \& Bowlds, 1990), and the results of this investigation add to knowledge of the factors that contribute to the development of these skills.

In general, we postulated that, through reciprocal interactions, parents and adolescents influence the developing character of one another's behavior. Considering the results of this study, we can now refine this statement. Reciprocal parent-child associations were most evident under conditions of adolescent negativity, particularly when behaviors were assessed with a 2-year time lag. When both the adolescent and his or her parents exhibited ineffective, coercive behavior, reciprocal influences prevailed, and, in agreement with Patterson's $(1982,1986)$ theory, the 
tenor of parent-adolescent interactions probably grew more negative over time relative to other study families. In families characterized by nurturant parental practices and a belligerent, disruptive adolescent, bidirectional influences also prevailed. In this case, disruptive, inflexible adolescent behavior influenced relative declines in nurturant parenting behavior over the study period, whereas adolescents whose parents used direct, positive, and rewarding control attempts probably exhibited less negative behavior over time than other adolescents in the study.

Regardless of parenting strategy, unidirectional influences (from parents to the adolescent) occurred when adolescents took a positive approach to resolving disagreements. Harshinconsistent parenting related negatively to flexible, involved adolescent behavior, indicating that this parenting strategy discouraged the development of effective adolescent problem-solving skills. Nurturant parenting, on the other hand, produced a statistically significant positive relationship with flexible, involved adolescent behavior. Thus, this child-rearing strategy fostered the development of effective adolescent problem-solving skills over time.

\section{Comparison of the 1-Year and 2-Year Measurement Interval Models}

Bidirectional effects can best be found when the measurement interval allows both actors sufficient time to experience significant behavior change (Gollob \& Reichardt, 1987; Sher et al., 1996). A too-short measurement interval may not allow enough time for both actors to experience change, and a too-long interval may allow cross-lagged patterns of association to go unnoticed. The best time interval for studying reciprocal parent-adolescent interactions is yet to be determined and thus remains a critical methodological issue. To further knowledge in this area, the present investigation used two different measurement intervals. We first tested the study hypotheses using a 2-year measurement interval and then retested the hypotheses using a 1-year measurement interval.

The results obtained with these two different measurement intervals underscore the importance of considering the length of the measurement interval in conjunction with the particular behavior under study. For example, when the interrelationships between parental behavior and flexible, involved adolescent problem-solving behavior were examined, the findings at both time lags were similar. Both sets of analyses produced unidirectional, parent-to-adolescent effects. Tests involving disruptive, inflexible adolescent behavior, however, resulted in different findings at different measurement intervals. The 1-year measurement models produced ambiguous results. One-year associations between nurturant parenting and disruptive, inflexible adolescent behavior were reciprocal from Year 1 to Year 2 and unidirectional between Years 2 and 3. The 1-year associations between disruptive adolescent behavior and harsh, inconsistent parenting were also unidirectional. From Year 1 to Year 2, adolescents showed a weak influence on parents' behavior, and parents influenced adolescent behavior from Year 2 to Year 3. In contrast, the 2-year time lag models uniformly supported the presence of reciprocal effects between disruptive, inflexible adolescent behavior and parental behavior.

Overall, therefore, the results of this study indicate that a 2year time lag may be preferable to a 1 -year measurement interval when examining reciprocal associations between parents and a belligerent, defiant adolescent. On the other hand, tests of the associations between flexible, involved adolescent behavior and parental behavior may require some other measurement interval to reveal reciprocal influences. Earlier we suggested that positive adolescent behavior is less stable over time than parental behavior (Conger et al., 1986) and thus more likely to change rather than influence change. This interpretation suggests that, if positive adolescent behavior does form reciprocal associations with parental behavior, it may occur over longer periods of time. However, future studies using varied measurement intervals are needed to fully examine these possibilities. For now, the results of this investigation indicate that, when assessed over 1 or 2 years, associations between parenting and effective adolescent problem-solving behavior are primarily unidirectional, from parents to adolescents.

These findings stand in contrast to earlier research that found reciprocal parent-adolescent influences using measurement intervals as short as 6 months (Maggs \& Galambos, 1993; Stice \& Barrera, 1995; Thomberry et al., 1991). At least two factors probably contribute to the difference in findings. First, all three earlier studies used adolescent self-reports in assessing both parental and adolescent behavior. Because the adolescent's dispositional characteristics were reflected in the reports of both parental and adolescent behavior, this measurement strategy probably resulted in more robust cross-lagged associations, even at relatively short time intervals. Second, the earlier studies each investigated reciprocal influences between parental behavior and various forms of adolescent delinquency. The adolescent behavior examined in the present study fell, for the most part, within the ranges of normal parent-adolescent interactions. If reciprocal associations form at different time intervals for different forms of behavior, more severe forms of behavior may well influence changes in others' behavior across shorter time intervals. Indeed, future studies of families whose adolescent children engage in severe forms of belligerent and disruptive problem-solving behavior or, conversely, exceptionally effective problem-solving behavior may find different patterns of parentchild effects, including significant results at shorter time intervals.

\section{Development of Adolescent Interpersonal Problem-Solving Skills}

The findings from this study show that parents play a significant role in the development of adolescent problem-solving skills. Negative parental behavior was associated with relative declines in adolescent problem-solving skills, whereas positive parental behavior was associated with relative increases in adolescent problem-solving skills. Furthermore, the lack of association between earlier effective adolescent problem-solving skills and later parental behavior supports others' contentions that efforts to improve an adolescent's interpersonal skills and alleviate family interaction problems should focus on parents and on the training of child-rearing skills (Dishion, Patterson, \& Kavanagh, 1992; Patterson, 1986). The finding of a negative relationship between harsh, inconsistent parenting and subsequent flexible, involved adolescent problem-solving behavior further suggests that efforts directed solely at improving an adolescent's interpersonal problem-solving skills may prove in- 
effective or, at best, short lived in the homes of harsh and inconsistent parents. Indeed, earlier investigations have reported that delinquent youths given social skills training tend not to use their improved skills when interacting with poorly skilled parents and subsequently show diminished social skills (Hazel, Schumaker, Sherman, \& Sheldon-Wildgen, 1982; Serna, Schumaker, Hazel, \& Sheldon, 1986).

In a similar light, the results of this investigation lobby for long-term support of parents with difficult children. Just as harsh, inconsistent parents posed a significant threat to flexible, involved adolescent behavior, a defiant, uncooperative adolescent posed a strong threat to parental nurturance. Gains from short-term parenting education programs might quickly extinguish in the face of a difficult adolescent. However, over time, effective parenting was associated with improvements in adolescent behavior such that parents of a disruptive, uncooperative adolescent who maintained a nurturant approach to child-rearing could potentially break or avoid being drawn into a pattern of reciprocal negativity. Of course, experimental tests of this hypothesis are needed.

Further investigation is also needed to determine the generalizability of this study's findings. For example, each of the families in this study consisted of two biological parents and an early- to middle-adolescent child. Because the nature of bidirectional parent-child interactions is likely to be developmental (Shaw \& Bell, 1993), the reciprocal effects examined in this study may operate differently in families at other stages of development. Also, it must be noted that the measures used in this study involved brief, 15- to 35-min "snapshots" of each family's interactions and, in some cases, showed only modest reliability. If viewed over hours, days, or weeks, or if assessed with more reliable measures, the relationships among the behaviors examined in this study may look very different. Similarly, this study examined bidirectional influences between parental management skills and adolescent responses to parents' control attempts. These are by no means the only interesting parentchild interactions, and, they are probably not the only forms of interaction capable of forming reciprocal parent-adolescent relationships (e.g., Conger \& $\mathrm{Ge}$, in press). Future investigations will need to study a broad range of parent and child behaviors to identify other unidirectional and bidirectional influences. Finally, our sample was composed of White middle-class and lower-middle-class rural families. Future studies must replicate these findings using samples consisting of families with varied structures, socioeconomic standing, and cultures.

\section{References}

Anderson, C. W. (1981). Parent-child relationships: A context for reciprocal developmental influence. The Counseling Psychologist, 9, 3544.

Bank, L., Dishion, T., Skinner, M., \& Patterson, G. R. (1990). Method variance in structural equation modeling: Living with "glop." In G. R. Patterson (Ed.), Depression and aggression in family interactions ( $\mathrm{pp}$. 247-279). Hillsdale, NJ: Erlbaum.

Bell, R. Q. (1968). A reinterpretation of the direction of effects in studies of socialization. Psychological Review, 75, 81-95.

Bell, R. Q., \& Harper, L. V. (1977). Child effects on adults. Hillsdale, NJ: Erlbaum.

Bentler, P. M. (1995). EQS structural equation program manual. Encino, CA: Multivariate Software.
Campbell, D. T., \& Fiske, D. W. (1959). Convergent and discriminant validation by the multitrait-multimethod matrix. Psychological Bulletin, 56, 81-105.

Collins, W. A. (1990). Parent-child relationships in the transition to adolescence: Continuity and change in interaction, affect, and cognition. In R. Montemayor, G. R. Adams, \& T. Gullota (Eds.), From childhood to adolescence: A transitional period? (Vol. 2, pp. 85106). Beverly Hills, CA: Sage.

Conger, R. D., Brainerd, D. W., Birch, L. L., Friedberg, P. J., \& Navarro, L. A. (1986). Assessing the quality of family observations: A comparative analysis. Journal of Marriage and the Family, 48, 361-373.

Conger, R. D., Conger, K. J., Elder, G. H., Jr., Lorenz, F. O., Simons, R. L., \& Whitbeck, L. B. (1992). A family process model of economic hardship and adjustment of early adolescent boys. Child Development, 63, 526-541.

Conger, R. D., Conger, K. J., Elder, G. H., Jr., Lorenz, F. O., Simons, R. L., \& Whitbeck, L. B. (1993). Family economic stress and adjustment of early adolescent girls. Developmental Psychology, 29, 206219

Conger, R. D., \& Elder, G. H., Jr. (1994). Families in troubled times. Adapting to change in rural America. New York: Aldine de Gruyter.

Conger, R. D., \& Ge, X. (in press). Conflict and cohesion in parentadolescent relations: Changes in emotional expression from early to mid-adolescence. In M. Cox \& J. Brooks-Gunn (Eds.), Conflict and closeness: The formation, functioning and stability of families. Mahwah, NJ: Erlbaum.

Conger, R. D., \& Simons, R. L. (1997). Life-course contingencies in the development of adolescent antisocial behavior: A matching law approach. In T. P. Thornberry (Ed.), Advances in criminological theory (Vol. 7, pp. 55-99). New Brunswick, NJ: Transaction.

Cook, T. D., \& Campbell, D. T. (1979). Quasi-experimentation: Design and analysis issues for field settings. Chicago: Rand McNally.

Davis, J. A. (1985). The logic of causal order. Newbury Park, CA: Sage.

DeBaryshe, B. D., Patterson, G. R., \& Capaldi, D. M. (1993). A performance model for academic achievement in early adolescent boys. Developmental Psychology, 29, 795-804.

Dishion, T. J., Patterson, G. R., \& Kavanagh, K. A. (1992). An experimental test of the coercion model: Linking theory, measurement, and intervention. In J. McCord \& R. Trembley (Eds.), The interaction of theory and practice: Experimental studies of interventions (pp. 253282). New York: Guilford Press.

Dubow, E. F., Tisak, J., Causey, D., Hryshko, A., \& Reid, G. (1991) A two-year longitudinal study of stressful life events, social support, and problem-solving skills: Contributions to children's behavioral and academic adjustment. Child Development, 64, 246-257.

Dwyer, J. H. (1983). Statistical models for the social and behavioral sciences. New York: Oxford University Press.

Finkel, S. E. (1995). Causal analysis with panel data. London: Sage.

Forehand, R., Long, N., Brody, G. H., \& Fauber, R. (1986). Home predictors of young adolescents' school behavior and academic performance. Child Development, 57, 1528-1533.

Gecas, V., \& Seff, M. A. (1990). Families and adolescents: A review of the 1980's. Journal of Marriage and the Family, 52, 941-958.

Glyshaw, K., Cohen, L. H., \& Towbes, L. C. (1989). Coping strategies and psychological distress: Prospective analyses of early and middle adolescents. American Journal of Community Psychology, 17, 607623.

Gollob, H. F., \& Reichardt, C. S. (1987). Taking account of time lags in causal models. Child Development, 58, 80-92.

Hauser, S. T., \& Bowlds, M. K. (1990). Stress, coping, and adaptation. In S. S. Feldman \& G. R. Elliot (Eds.), At the threshold: The developing adolescent (pp. 388-413). Cambridge, MA: Harvard University Press.

Hazel, J. S., Schumaker, J. B., Sherman, J. A., \& Sheldon-Wildgen, J. B. 
(1982). Group training for social skills: A program for court adjudicated youths. Criminal Justice and Behavior, 9, 35-53.

Hill, J. P. (1988). Adapting to menarche: Familial control and conflict. In M. R. Gunnar (Ed.), Minnesota Symposia on Child Psychology (Vol. 21, pp. 43-77). Hillsdale, NJ: Erlbaum.

Hill, J. P. (1993). Recent advances in selected aspects of adolescent development. Journal of Child Psychology and Psychiatry, 34, 6999.

Jöreskog, D. G., \& Sörbom, D. (1989a). LISREL VII: A guide to the program and applications. Chicago: SPSS.

Jöreskog, D. G., \& Sörbom, D. (1989b). LISREL VII: User's reference guide. Mooresville, IN: Scientific Software.

Kenny, D. A. (1991). A general model of consensus and accuracy in interpersonal perception. Psychological Review, 98, 155-163.

Kobak, R. R., Cole, H. E., Ferenz-Gillies, R., Fleming, W. S., \& Gamble, W. (1993). Attachment and emotion regulation during mother-teen problem-solving: A control theory analysis. Child Development, 64, 231-245.

Lorenz, F. O., Conger, R. D., Simons, R. L., \& Whitbeck, L. B. (1995). The effects of unequal variances and covariances in simultaneous inference: The case of hostility and marital quality. Journal of Marriage and the Family, 57, 1049-1064

Lorenz, F. O., Conger, R. D., Simons, R. L., Whitbeck, L. B., \& Elder, G. H., Jr. (1991). Economic pressure and marital quality: An illustration of the method variance problem in the causal modeling of family processes. Journal of Marriage and the Family, 53, 375-388.

Lytton, H. (1990). Child and parent effeets in boys' conduct disorder: A reinterpretation. Developmental Psychology, 26, 683-697.

Maggs, J. L., \& Galambos, N. L. (1993). Alternative structural models for understanding adolescent problem behavior in two-earner families. Journal of Early Adolescence, 13, 79-101.

McCubbin, H. I., Needle, R. H., \& Wilson, M. (1985). Adolescent health risk behaviors: Family stress and adolescent coping as critical factors. Family Relations, 34, 51-62.

Melby, J., Conger, R. D., Book, R., Rueter, M. A., Lucy, L., Repinski, D., Ahrens, K., Black, D., Huck, S., Mutchler, L., Rogers, S., Ross, J. F., \& Stravos, T. (1989). Iowa Family Interaction Rating Scales. Ames: Iowa State University.

Mitchell, S. K. (1979). Interobserver agreement, reliability, and generalizability of data collected in observational studies. Psychological Bulletin, 86, 376-390.

Montemayor, R. (1983). Parents and adolescents in conflict: All families some of the time and some families most of the time. Journal of Early Adolescence, 3, 83-103.

Paikoff, R. L., \& Brooks-Gunn, J. (1991). Do parent-child relationships change during puberty? Psychological Bulletin, 110, 47-66.

Patterson, G. R. (1982). Coercive family process. Eugene, OR: Castalia.

Patterson, G. R. (1986). Performance models for antisocial boys. American Psychologist, 41, 432-444.

Patterson, G. R., \& Bank, L. (1989). Some amplifying mechanisms for pathologic process in families. In M. R. Gunnar \& E. Thelen (Eds.), Minnesota Symposia on Child Psychology (Vol. 22, pp. 167-209). Hillsdale, NJ: Erlbaum.

Patterson, G. R., Bank, L., \& Stoolmiller, M. (1990). The preadolescent's contribution to disrupted family process. In R. Montemayor, G. R. Adams, \& T. P. Gullotta (Eds.), From childhood to adolescence: A transitional period? (pp. 107-133). Newbury Park, CA: Sage.

Reid, W. J., \& Crisafulli, A. (1990). Marital discord and child behavior problems: A meta-analysis. Journal of Abnormal Child Psychology; I8, 105-117.

Robin, A. L., Koepke, T., \& Moye, A. ( 1990). Multidimensional assessment of parent-adolescent relations. Psychological Assessment, 4, 451-459.

Rubenstein, J. L., \& Feldman, S. S. (1993). Conflict-resolution behavior in adolescent boys: Antecedents and adaptational correlates. Journal of Research on Adolescence, 3, 41-66.

Rueter, M. A., \& Conger, R. D. (1995a). Antecedents of parent-adolescent disagreements. Journal of Marriage and the Family, 57, 435448 .

Rueter, M. A., \& Conger, R. D. (1995b). Interaction style, problem solving behavior, and family problem solving effectiveness. Child Development, 66, 98-115.

Sameroff, A. J. (1975). Early influences on development: Fact or fancy? Merrill-Palmer Quarterly, 21, 267-294.

Sanders, M. R., Dadds, M. R., Johnston, B. M., \& Cash, R. (1992), Childhood depression and conduct disorder: I. Behavioral, affective, and cognitive aspects of family problem-solving interactions. Journal of Abnormal Psychology, 101, 495-504.

Serna, L. A., Schumaker, J. B., Hazel, J. S., \& Sheldon, J. B. (1986) Teaching reciprocal social skills to parents and their delinquent adolescents. Journal of Clinical and Child Psychology, 15, 64-77.

Shaw, D. S., \& Bell, R. S. (1993). Developmental theories of parental contributors to antisocial behavior. Journal of Abnormal Child Psychology, 21, 493-518.

Sher, K. J., Wood, M. D., Wood, P. K., \& Raskin, G. (1996). Alcohol outcome expectancies and alcohol use: A latent variable cross-lagged panel study. Journal of Abnormal Psychology, 105, 561-574.

Shrout, P. E., \& Fleiss, J. L. (1979). Intraclass correlations: Uses in assessing rater reliability. Psychological Bulletin, 86, 420-428

SPSS, Inc. (1994). SPSS 6.1 syntax reference guide. Chicago: Author.

Steinberg, L. (1981). Transformations in family relations at puberty. Developmental Psychology, 60, 1052-1067.

Stice, E., \& Barrera, M., Jr. (1995). A longitudinal examination of the reciprocal relations between perceived parenting and adolescents' substance use and externalizing behaviors. Developmental Psychology, 31, 322-334.

Suen, K., \& Ary, D. (1989). Analyzing quantitative behavioral observation data. Hillsdale, NJ: Erlbaum.

Thompson, K. M., \& Wilsnack, R. W. (1987). Parental influence on adolescent drinking: Modeling attitudes, or conflict? Journal of Youth and Adolescence, 21, 609-623.

Thornberry, T. P. (1987). Toward an interactional theory of delinquency. Criminology, 25, 863-891.

Thornberry, T. P., Lizotte, A. J., Krohn, M. D., Farnworth, M., \& Jang, S. J. (1991). Testing interactional theory: An examination of reciprocal causal relationships among family, school, and delinquency. Journal of Criminal Law and Criminology, 82, 3-33.

Thornberry, T. P., Lizotte, A. J., Krohn, M. D., Farnworth, M., \& Jang, S. J. (1994). Delinquent peers, beliefs, and delinquent behavior: A longitudinal test of interactional theory. Criminology, 32, 47-83.

Vuchinich, S., Bank, L., \& Patterson, G. R. (1992). Parenting, peers, and the stability of antisocial behavior in preadolescent boys. Developmental Psychology, 28, 510-521.

Werner, E. E., \& Smith, R. S. (1992). Overcoming the odds: High risk children from birth to adulthood. Ithaca, NY: Cornell University Press.

Received June 6, 1996

Revision received January 28, 1998 Accepted January 28, 1998 